\title{
Mechanism of the Electronic Stabilization of the 3MR and Divalent Carbon of Bis(Diisopropylamino)Cyclopropenylidene
}

Lucius E. Johnson and Donald B. DuPré*

Department of Chemistry, University of Louisville, Louisville, Kentucky, 40292

\section{Supporting Information.}

I. Complete list of authors for Reference 36. Gaussian 03, Revision C.02, Frisch, M. J.; Trucks, G. W.; Schlegel, H. B.; Scuseria, G. E.; Robb, M. A.; Cheeseman, J. R.;

Montgomery, Jr., J. A.; Vreven, T.; Kudin, K. N.; Burant, J. C.; Millam, J. M.; Iyengar, S. S.; Tomasi, J.; Barone, V.; Mennucci, B.; Cossi, M.; Scalmani, G.; Rega, N.; Petersson, G. A.; Nakatsuji, H.; Hada, M.; Ehara, M.; Toyota, K.; Fukuda, R.; Hasegawa, J.; Ishida, M.; Nakajima, T.; Honda, Y.; Kitao, O.; Nakai, H.; Klene, M.; Li, X.; Knox, J. E.; Hratchian, H. P.; Cross, J. B.; Bakken, V.; Adamo, C.; Jaramillo, J.; Gomperts, R.; Stratmann, R. E.; Yazyev, O.; Austin, A. J.; Cammi, R.; Pomelli, C.; Ochterski, J. W.; Ayala, P. Y.; Morokuma, K.; Voth, G. A.; Salvador, P.; Dannenberg, J. J.; Zakrzewski, V. G.; Dapprich, S.; Daniels, A. D.; Strain, M. C.; Farkas, O.; Malick, D. K.; Rabuck, A. D.; Raghavachari, K.; Foresman, J. B.; Ortiz, J. V.; Cui, Q.; Baboul, A. G.; Clifford, S.; Cioslowski, J.; Stefanov, B. B.; Liu, G.; Liashenko, A.; Piskorz, P.; Komaromi, I.; Martin, R. L.; Fox, D. J.; Keith, T.; Al-Laham, M. A.; Peng, C. Y.; Nanayakkara, A.; Challacombe, M.; Gill, P. M. W.; Johnson, B.; Chen, W.; Wong, M. W.; Gonzalez, C.; and Pople, J. A.; Gaussian, Inc., Wallingford CT, 2004.

II. Atomic coordinates in Gaussian-type input form excerpted from Gaussian03 files for optimized structures 1-3. Nothing is implied about the level of precision of calculations in the number of significant figures produced in the standard formatting of computations with the Gaussian03 program. Level of theory: B3LYP/6-31G(d,p).

1. Cyclopropenylidene (1) with $\mathrm{R}=\mathrm{H}$

$$
\begin{array}{ll}
\text { C } & 0.017345663,-0.9412928957,0.0012071276 \\
\text { C } & 0.6562355519,0.3374291537,-0.0008699274 \\
\text { C } & -0.6686901609,0.3126675414,-0.0000130907 \\
\text { H } & -1.6097401286,0.8469596449,0.0000129293 \\
\text { H } & 1.5803938045,0.9002175583,-0.0019575859
\end{array}
$$

2. Bis(dimethylamino)cyclopropenylidene (2) with $\mathrm{R}=\mathrm{NMe}_{2}$

$$
\begin{array}{ll}
\text { C } & -0.1274958356,-0.7073764905,-0.4390349412 \\
\text { C } & 0.562416585,-0.322762962,-1.6119027349 \\
\text { C } & 0.5423295346,0.4698937341,-0.4411557444 \\
\text { N } & -0.8757203319,-1.672786314,0.1281152153 \\
\text { N } & 0.9910582143,1.6077181879,0.1225126575 \\
\text { C } & 0.5088960455,2.0811113339,1.4064126809 \\
\text { H } & 1.324699367,2.5596634749,1.9606523399
\end{array}
$$




$\begin{array}{ll}\mathrm{H} & -0.3057120193,2.8139385577,1.3016481332 \\ \mathrm{H} & 0.1434582331,1.2380512866,1.995203107 \\ \mathrm{C} & 1.6912734318,2.5659713751,-0.7230470348 \\ \mathrm{H} & 2.5838542604,2.9448537675,-0.211354357 \\ \mathrm{H} & 1.9896066786,2.0610794847,-1.6425077404 \\ \mathrm{H} & 1.0518903702,3.4226731281,-0.9807554459 \\ \mathrm{C} & -1.5257112059,-1.4977806539,1.4133466274 \\ \mathrm{H} & -2.5722418552,-1.1724877983,1.3106983158 \\ \mathrm{H} & -1.518506916,-2.4424535393,1.9694691804 \\ \mathrm{H} & -0.9863901934,-0.7515615398,1.9992360695 \\ \mathrm{C} & -1.3423795731,-2.7670102848,-0.7135463054 \\ \mathrm{H} & -0.7576708301,-2.767511699,-1.6341132116 \\ \mathrm{H} & -1.2102585964,-3.7263604946,-0.1994665937 \\ \mathrm{H} & -2.4060675692,-2.656684057,-0.969540193\end{array}$

3. Bis(diisopropylamino)cyclopropenylidene (3) with $\mathrm{R}=\mathrm{N}(i-\mathrm{Pr})_{2}$.

C $\quad 0.0557181529,0.6352484005,-0.8482479916$

C $\quad-0.1407503054,-0.0859868013,-2.0466589988$

C $\quad-0.1673980084,-0.7035229514,-0.7766571659$

$\mathrm{N} \quad 0.2877456309,1.8633433521,-0.3363153538$

$\mathrm{N} \quad-0.3201706388,-1.8832660902,-0.137126155$

C $\quad-0.3063357274,-1.8953826534,1.3416481839$

$\mathrm{H} \quad 0.292151608,-1.0181329479,1.6091113087$

C, $\quad-0.6091818285,-3.0428564845,-1.0213740753$

$\mathrm{H} \quad-0.7932596494,-2.5696089724,-1.9904777322$

C $\quad 0.4759970448,1.9989436159,1.1242622525$

$\mathrm{H} \quad-0.0751430309,1.1504315961,1.5432596527$

C $\quad 0.4464416013,2.9434352563,-1.3454120601$

$\mathrm{H} \quad 0.4992014045,2.3899275064,-2.2876746776$

C $\quad-0.1561502724,3.2609131633,1.7235863202$

$\mathrm{H} \quad-0.0761218263,3.216880015,2.8145424378$

$\mathrm{H} \quad 0.347264805,4.1751613568,1.3982998702$

$\mathrm{H} \quad-1.2150060691,3.3377479631,1.4642770447$

C $\quad 0.4087990854,-3.1066437677,1.9522128669$

$\mathrm{H} \quad 1.4227040455,-3.2110989522,1.5579991415$

H $\quad 0.478341366,-2.9712590238,3.0363547909$

$\mathrm{H} \quad-0.1292396146,-4.041858242,1.7762114712$

C $\quad 1.9453746683,1.8383093003,1.5544819485$

$\mathrm{H} \quad 2.5582142545,2.6856084655,1.2371888287$

$\mathrm{H} \quad 2.0149276207,1.7653752216,2.6456695762$

$\mathrm{H} \quad 2.3743001751,0.9283489447,1.1241581678$

C $\quad-1.7040197312,-1.6907373233,1.953660902$

H $\quad-2.3497332792,-2.5579245181,1.7949034192$

H $\quad-1.6242326695,-1.5265999499,3.0341889261$ 


$\begin{array}{ll}\text { H } & -2.1927843282,-0.8173410313,1.5115410033 \\ \text { C } & 1.7525226261,3.7376912231,-1.2129386401 \\ \text { H } & 2.6205124465,3.0728368956,-1.2032074613 \\ \text { H } & 1.8528573169,4.4089134647,-2.0722356396 \\ \text { H } & 1.7810514013,4.3596831787,-0.3128878728 \\ \text { C } & -1.880444527,-3.8156076034,-0.6458996209 \\ \text { H } & -1.782248166,-4.3601591065,0.2983471093 \\ \text { H } & -2.7426810526,-3.1471804285,-0.5732005039 \\ \text { H } & -2.0934756464,-4.5555842921,-1.4243928103 \\ \text { C } & -0.7828905166,3.8613834767,-1.4433410685 \\ \text { H } & -1.6964326033,3.2668630308,-1.5314441877 \\ \text { H } & -0.883623962,4.5267622847,-0.5820052094 \\ \text { H } & -0.7018293622,4.4889695986,-2.3377273904 \\ \text { C } & 0.6003721047,-3.9729812823,-1.2093219256 \\ \text { H } & 1.4899834275,-3.3932610343,-1.4706499298 \\ \text { H } & 0.8215129283,-4.5647675735,-0.3173223177 \\ \text { H } & 0.4014373155,-4.6725076958,-2.0287420171\end{array}$

III. More detailed narrative about the methodology of the quantum theory of atoms in molecules (QTAIM) used in the main manuscript.

The equilibrium geometries of the molecules of this study were fully optimized, including normal mode frequency analysis, using density functional theory (DFT) at B3LYP/6-31G(d,p $)^{1,2}$, as implemented in Gaussian03. ${ }^{3}$

The resultant electron density, $\rho$, obtained from the wave function of all optimized structures was analyzed with the quantum theory of atoms in molecules (QTAIM) $)^{4,5}$ in which an atom in a molecule is rigorously defined as a quantum mechanical entity bounded by a three dimensional surface of zero flux in the gradient, $\nabla \rho$, of the electron density $\rho$. That is, the dot product of $\nabla \rho(\mathrm{r})$ and the normal to this surface is zero $-\nabla \rho(\mathrm{r}) \cdot \mathbf{n}(\mathrm{r})=0$ - for all points $\mathrm{r}$ on the atomic boundary. Given this delineation of the boundaries of an atom, the net charge, dipole and quadrupole of an individual atom can be obtained by integration of moments of the electron density over the atomic volume-referred to as the atomic basin. 
A chemical bond between two atoms is distinguished by a path of maximal electron density between the nuclear attractors with a $(3,-1)$ critical point (saddle point) on the interatomic surface (IAS) joining the two atoms. The properties of the bond critical point (BCP) serve to categorize different types of chemical bonds. The covalent bond generally manifests large values of the electron density, $\rho_{b}$, at the BCP. The Laplacian, $\nabla^{2} \rho_{b}$, which may be written in terms of the eigenvalues of the Hesssian of $\rho$ as $\nabla^{2} \rho=\lambda_{1}+\lambda_{2}+\lambda_{3}$, where $\lambda_{1} \leq \lambda_{2} \leq \lambda_{3}$, is also generally large and negative at this point. ${ }^{4,5,6}$ The latter property reflects the dominance of contraction of electron density along the bond path (BP) in covalent bonds. In this case, the electronic charge is concentrated between nuclei and thus shared.

$\pi$-Type concentration of electron density is evident in double, or partially double, bonds in the distortion from circular symmetry of the inwards curvature of $\rho$ about the bond axis. For like atoms, the value of $\varepsilon=\left(\lambda_{1} / \lambda_{2}\right)-1$ at the BCP is a good measure of this ellipticity. ${ }^{7,8}$ The use of this parameter for unlike atoms, particularly those with substantially different electronegativities, could be misleading and more thorough mapping $^{9,10}$ is needed of the possible change of orientation along the bond path of the two eigenvectors, with eigenvalues $\lambda_{1}$ and $\lambda_{2}$, associated with axial curvature of $\rho$ about the bond path (BP).

Examination of the properties of the Laplacian can also uncover regions of valence shell charge concentration (VSCC) where the electron density is curving inwards (contracting) in all directions. ${ }^{4,7}$ These regions are characterized by the presence of $(3,-3)$ 
critical points (CPs) where all eigenvalues $\lambda_{i}$ of the Laplacian are negative. These CPs may or may not be directed towards bonded atoms. In the latter case, the accumulations of charge map onto the chemist's idea of non-bonded lone-pairs. ${ }^{4,7}$ VSCCs may be further characterized by their spherical surface $\operatorname{area}^{4}$ about the nucleus and radial thickness outwards of the nucleus as given by $\mu_{3}$, the curvature of $\nabla^{2} \rho$ perpendicular to the surface of this sphere. ${ }^{4}$ A larger value of $\mu_{3}$ is indicative of a thinner radial concentration of charge. The band of VSCC of an atom in a molecule may be breached by local regions of minimal concentration characterized by $(3,+1)$ CPs where two curvatures of $\rho$, tangential to the surface, are positive. Such regions of local charge depletion are significant as they expose the nucleus to nucleophilic attack.

Molecules with closed surfaces also exhibit ring critical points (RCPs), characterized by $(3,+1) \mathrm{CPs}$; or cage critical points $(\mathrm{CCPs})$, characterized by $(3,+3) \mathrm{CPs}$. In the case of a RCP, electron density is depleted along two of the orthogonal eigenvectors that define the ring surface and concentrated along the other, normal to the surface. For CCPs, electron density is depleted in all directions.

The degree of localization, $\lambda(\mathrm{A})$, of electrons within the QTAIM-defined atomic basins, $\mathrm{A}$, and their delocalization, $\delta(\mathrm{A}, \mathrm{B})$, into the basins of other atoms, $\mathrm{B}$, were also calculated as described by Fradera et al. ${ }^{11}$ and Biegler-Konig and Schonbohm. ${ }^{12}$ These calculations are based on integrations of the electron-pair density over individual atomic basins and between bonded and nonbonded atomic basins within the molecule. The indices provide a measure of electron-pair sharing arising from exchange correlation by 
averaging the effect of following the spread of the Fermi hole of a representative electron which excludes a like amount of density from another same-spin electron. Coulomb correlation is also introduced in our calculations through density functional theory.

The QTAIM atom, as defined by the zero flux condition above, has also been shown ${ }^{4}$ to obey an atomic version of the virial theorem: $-2 T(A)=V(A)$, where $T(A)$ and $V(A)$ are the kinetic and potential energies, respectively, of atom $\mathrm{A}$. The atomic energy $\mathrm{E}(\mathrm{A})=$ $\mathrm{T}(\mathrm{A})+\mathrm{V}(\mathrm{A})=-\mathrm{T}(\mathrm{A})=1 / 2 \mathrm{~V}(\mathrm{~A})$, within integration error. For more detailed consideration of the physics of changes of an atom across molecular analogs, the atomic virial, $\mathcal{V}(\mathrm{A})$, of the Ehrenfest force was calculated and separated into a part acting on the electrons within an atomic basin $\mathrm{A}, \mathcal{V}_{b}(\mathrm{~A})$, and a part due to the maintenance of the atomic surface(s), $\mathcal{V}_{s}(\mathrm{~A})$, between or among other atoms. ${ }^{4,13}$

QTAIM analysis was performed with the AIM2000 program $^{12}$ using wave functions generated with the Gaussian electronic structure package.

\section{References:}

1. Becke, A. D. J. Chem. Phys. 1993, 98, 5648-5652.

2. Lee, C.; Yang, W.; Parr, R. G. Phys. Rev. 1988, B37, 785-789.

3. Frisch, M. J. et al. Gaussian03, Revision C.02; Gaussian, Inc.: Wallingford CT, 2004.

4. Bader, R. F. W. Atoms in molecules. A quantum theory; Clarendon Press: Oxford, 1990.

5. Popelier, P. Atoms in molecules. An introduction; Prentice Hall: New York, 2000. 
6. Bader, R. F. W.; Essén, H. J. Chem. Phys. 1984, 80, 1943-1960.

7. Bader, R. F. W.; MacDougall, P. J.; Lau, C. D. H. J. Am. Chem. Soc. 1984, 106, 1594-1605.

8. Bader, R. F. W.; Slee, T. S.; Cremer, D.; Kraka, E. J. Am. Chem. Soc. 1983, 105, $5061-5068$.

9. Cheeseman, J. R.; Carroll, M. T.; Bader, R. F. W. Chem. Phys. Lett. 1988, 143, 450-458.

10. Tafipolsky, M.; Scherer, W.; Ofele, K.; Artus, G.; Pedersen, B.; Herrmann, W. A.; McGrady, G. S. J. Am. Chem. Soc. 2002, 124, 5865-5880.

11. Fradera, X.; Austen, M. A.; Bader, R. F. W. J. Phys.Chem. A. 1999, 103, 304-314.

12. Biegler-Konig, F.; Schonbohm, J. J. Compt. Chem. 2002, 23, 1489-1494.

13. Bader, R. F. W. Monatsh. Chem. 2005, 136, 819-854. 